\title{
Anti-inflammatory effect of bee venom in an allergic chronic rhinosinusitis mouse model
}

\author{
SEUNG-HEON SHIN ${ }^{1}$, MI-KYUNG YE ${ }^{1}$, SUNG-YONG CHOI ${ }^{1}$ and KWAN-KYU PARK ${ }^{2}$ \\ Departments of ${ }^{1}$ Otolaryngology-Head and Neck Surgery, and ${ }^{2}$ Pathology, \\ School of Medicine, Catholic University of Daegu, Daegu 42472, Republic of Korea
}

Received October 27, 2017; Accepted February 28, 2018

DOI: $10.3892 / \mathrm{mmr} .2018 .8720$

\begin{abstract}
Bee venom (BV) has long been used as anti-inflammatory agent in traditional oriental medicine; however, the effect of BV on chronic rhinosinusitis (CRS) is not commonly studied. The aim of the present study was to determine the anti-inflammatory effect of BV on an allergic CRS mouse model. An allergic CRS mouse model was established following the administration of ovalbumin with Staphylococcus aureus enterotoxin B (SEB) into the nose. A total of 0.5 or $5 \mathrm{ng} / \mathrm{ml}$ of BV were intranasally applied 3 times a week for 8 weeks. Histopathological alterations were observed using hematoxylin and eosin, and Periodic acid Schiff staining. The levels of inflammatory cell infiltration, interleukin (IL)-4, IL-10 and interferon (INF) $\gamma$ in nasal lavage fluid (NLF) were measured. Nuclear factor (NF)- $\kappa \mathrm{B}$ and activator protein (AP)-1 expressions were also determined by immunohistochemical staining. The group treated with BV had significantly decreased inflammatory cell infiltration and PAS-positive cells. The levels of INF- $\gamma$, and neutrophil and eosinophil counts in NLF were significantly decreased, and the SEB-induced NF- $\kappa \mathrm{B}$ and AP-1 expressions in mouse nasal mucosa were significantly suppressed by 0.5 and $5 \mathrm{ng} / \mathrm{ml} \mathrm{BV}$. Thus, BV exerted significant anti-inflammatory effects in an allergic CRS mouse model and may have potential value for the treatment of CRS.
\end{abstract}

\section{Introduction}

Chronic rhinosinusitis (CRS) is a complex inflammatory disease of nose and paranasal sinus mucosa. Pathogenesis of CRS remain unclear with numerous hypothesis have been proposed, including bacterial superantigen, biofilm,

Correspondence to: Dr Seung-Heon Shin, Department of Otorhinolaryngology-Head and Neck Surgery, School of Medicine, Catholic University of Daegu, 33 Duryugongwon-ro 17-gil, Nam-Gu, Daegu 42472, Republic of Korea

E-mail: hsseung@cu.ac.kr

Key words: Staphylococcus enterotoxin B, bee venom, chronic rhinosinusitis, mouse model fungal infection, and T-cell immune dysfunction (1-3). Staphylococcus aureus produces proteins that act both as superantigens and toxins. Staphylococcal enterotoxin B (SEB) is commonly associated in the development of CRS with nasal polyp and specific IgE against SEB is more frequently detected in patients with nasal polyps than without nasal polyps (4). Nasal exposure to SEB induce nasal polypoid lesion with allergic rhinosinusitis in mice (5). Level of interleukin (IL)-5, eotaxin in nasal lavage fluid (NLF) and number of secretory cells in nasal mucosa were increased in allergic rhinosinusitis model. Animal models of the CRS response to various pathogens have been studied to elucidate the mechanisms leading to the development of inflammation and the therapeutic effect of newly developed agents.

Bee venom (BV) has been used as a traditional oriental medicine to treat chronic inflammatory diseases and malignant diseases for long time (6). BV contains a variety of peptide, enzymes, biologically active amines and non-peptide components with radioprotective, anti-mutagenic, anti-inflammatory, anti-nociceptive, and anti-cancer properties (6-9). Melittin and apamin, the main components of BV, have anti-inflammatory activity that inhibit cyclooxygenase-2 and phospholipase A2 (PLA2) activity, and decrease levels of tumor necrosis factor- $\alpha$, IL-1, IL-6, and nitric oxide (10). Our previous study showed that BV inhibits airborne allergen-induced cytokine production from nasal epithelial cells by inhibiting the NF- $\kappa \mathrm{B}$ and AP-1 pathways (11).

Animal models have demonstrated the capability of anti-inflammatory and ant-bacterial activity of BV (12). However, due to the BV has dose dependent immunosuppressive and immunostimulatory property, the determination of optimal concentration without side effect is an important for clinical application of BV. In this study, we used a mouse model of allergic CRS to evaluate the effect of BV intranasal instillation on nasal mucosal inflammation.

\section{Materials and methods}

Preparation of $B V$. Pure honeybee (Apis mellifera) venom was obtained from the National Institute of Agricultural Science and Technology, Suwon, Korea. BV was collected using a specialized collector without damaging the honeybee by an established electric shock method. BV was dissolved in distilled water and centrifuged at $12,000 \mathrm{x}$ g for $10 \mathrm{~min}$ 
to remove insoluble materials. The BV was lyophilized by freeze drying and stored (13). Bioactive components of BV used in this experiment, such as melittin, apamin and other major active ingredients, were confirmed with size exclusion gel chromatography (AKTAexplorer, Pharmacia, Pleasanton, CA, USA) by dissolving in $0.1 \mathrm{M}$ ammonium formate as the eluent.

Animals and experimental protocol. An allergic CRS mouse model was established as described previously with slight modification (5). Female BALB/c mice, which were six-weeks old and free of murine specific pathogens, were obtained from Hyosung Science (Daegu, Republic of Korea). They were maintained under standard laboratory conditions in a pathogen-free cage. Food and water were freely available and all animal experiments were approved by the Institutional Review Board of Animal Experiments of Daegu Catholic University Medical Center (Daegu, Republic of Korea) and were conducted in accordance with the guidelines of the Institutional Review Board of Animal Experiments of Daegu Catholic University Medical Center.

Mice were sensitized by administration of an intraperitoneal injection of ovalbumin (OVA, grade V; Merck KGaA, Darmstadt, Germany) $75 \mu \mathrm{g}$ in $200 \mu \mathrm{l}$ of phosphate buffer solution (PBS) containing $2 \mathrm{mg}$ of aluminum hydroxide (Merck KGaA) in a total volume of $200 \mu \mathrm{l}$ on days $0,7,14$, and 21 , followed by a daily intranasal instillation from days 22 to 25 with $500 \mathrm{ug}$ of OVA diluted in $20 \mathrm{ul}$ of PBS. Thereafter, inflammation was maintained in the experimental mice by the subsequent nasal instillation of OVA three times a week for 4 consecutive weeks. To develop allergic CRS, in addition to OVA, selected group of mice were intranasally challenged weekly with 5 or $500 \mathrm{ng} / \mathrm{ml}$ of staphylococcus aureus enterotoxin B (SEB) (Merck KGaA) form 9 weeks through 16 weeks after OVA instillation. To determine the effect of BV on the development of allergic CRS, 0.5 or $5 \mathrm{ng} / \mathrm{ml}$ of BV were intranasally applied three times a week from 9 weeks through 16 weeks. At day 113, mice were sacrificed for further study (Fig. 1).

The study groups were designed as follows: PBS instillation only (group I), OVA with $5 \mathrm{ng} / \mathrm{ml}$ of SEB instillation (group II), OVA with $5 \mathrm{ng} / \mathrm{ml}$ of SEB instillation which treated with $0.5 \mathrm{ng} / \mathrm{ml}$ of BV (group III), OVA with $5 \mathrm{ng} / \mathrm{ml}$ of SEB instillation which treated with $5 \mathrm{ng} / \mathrm{ml} \mathrm{BV}$ instillation (group IV), OVA with $500 \mathrm{ng} / \mathrm{ml}$ of SEB instillation (group V), OVA with $500 \mathrm{ng} / \mathrm{ml}$ of SEB instillation treated with $0.5 \mathrm{ng} / \mathrm{ml}$ of BV (group VI), and OVA with $500 \mathrm{ng} / \mathrm{ml}$ of SEB instillation treated with $5 \mathrm{ng} / \mathrm{ml}$ of BV (group VII). Each experimental group included 7 mice.

Evaluation of OVA specific IgE level and allergic behavior. Blood was collected from the inferior vena cava and serum was obtained by centrifugation. OVA-specific IgE level in serum was measured using ELISA (Pharmingen, San Diego, CA, USA). The number of sneezing and nasal rubbing motion were recorded by a two blinded observers after the final instillation of BV for $15 \mathrm{~min}$ the day before sacrifice and compared with that of the PBS instillation group. The total no. of sneezing and rubbing motion were added and the average values of the observers' measurements were determined as the allergic behavior.
Nasal lavage fluid study. NLF was collected by an 18-gauge catheter through partial tracheal resection. The catheter was inserted into the tracheal opening in the direction of the upper airway and into the nasopharynx. Nasal passages were gently perfused with $1 \mathrm{ml}$ cold PBS and collected in a tube. The collected fluid was centrifuged at $2000 \mathrm{rpm}$ for $7 \mathrm{~min}$ at $4^{\circ} \mathrm{C}$, and the supernatant was stored at $-70^{\circ} \mathrm{C}$. Amounts of interleukin (IL)-4, IL-10 and interferon-gamma (INF- $\gamma$ ) in NLF were measured using an ELISA quantitation kit (R\&D Systems, Inc., Minneapolis, MN, USA). The limit of detection was $<2 \mathrm{pg} / \mathrm{ml}$ of each cytokine. For differential cell counts of NLF, $1 \mathrm{ml}$ of NLF was centrifuged and pellet was resuspended in $100 \mathrm{ul}$ of PBS. Then $10 \mathrm{ul}$ of cell suspension was stained with the May-Grunwald-Giemsa stain and cells differentiated into eosinophils, neutrophils, lymphocytes, and other cells as average number of cells in five high power fields.

Histological evaluation of nasal mucosa. Mice were painlessly sacrificed with a lethal dose $(120 \mathrm{mg} / \mathrm{kg})$ of intraperitoneally administered pentobarbital sodium $24 \mathrm{~h}$ after the last intranasal provocation. Specimens were decalcified until they were soft in $0.25 \mathrm{~mol} / \mathrm{l}$ ethylenediaminetetraacetic acid for $24 \mathrm{~h}$. The tissue was dehydrated and processed according to the paraffin-embedding procedure, the tissue was cut in coronal section with a thickness of 5- $\mu \mathrm{m}$. Three anatomically similar sections were chosen from each mouse for analysis. The first section, the most anterior, was at the level of the maxillary sinuses. The second section, more posterior, was at the end of the maxillary sinuses and the beginning of the complex ethmoid turbinals. The third section, most posterior, contained the brain superiorly.

Appearance of inflammatory cell infiltration and epithelial thickness was quantified in hematoxylin and eosin stained sections at x200 and x400 magnification. Goblet cell numbers were quantified in Periodic acid Schiff (PAS) stain at x200 magnification. All tissue sections were examined blindly with respect to the source of the tissue and average number of positive stained cell were determined at three different mucosal areas for each of the three sections per mouse.

The presence or absence of submucosal inflammatory cell infiltration was quantified into four categories-0: no, 1: mild, occasional scattered inflammatory cells, 2: moderate, 3: severe, diffuse infiltration of inflammatory cells. Average thickness of epithelial layer was directly measured on a scale of magnification $\mathrm{x} 400$ at four different areas for each of the three different sections in each mouse and average number of goblet cells was counted at four different areas per $\mathrm{mm}^{2}$ of nasal mucosa by an eyepiece reticule. Images were digitalized on a computer through an Olympus video camera (Olympus Corporation, Tokyo, Japan) and were analyzed with DP controller software (v2.2.1.227).

The effect of BV on the expression of transcriptions factors, immunohistochemical staining was performed by using the avidin-biotin complex method. Deparaffinized sections with blocked endogenous peroxidase activity were incubated with primary antibodies for $1 \mathrm{~h}$ at room temperature (nuclear factor (NF) $-\kappa B$ p65, activator protein (AP)-1 c-Jun; Santa Cruz Biotechnology, Inc., Dallas, TX, USA). They were then incubated with biotinylated secondary antibody, followed by avidin-biotin-peroxydase complex. Lastly, the sections were 


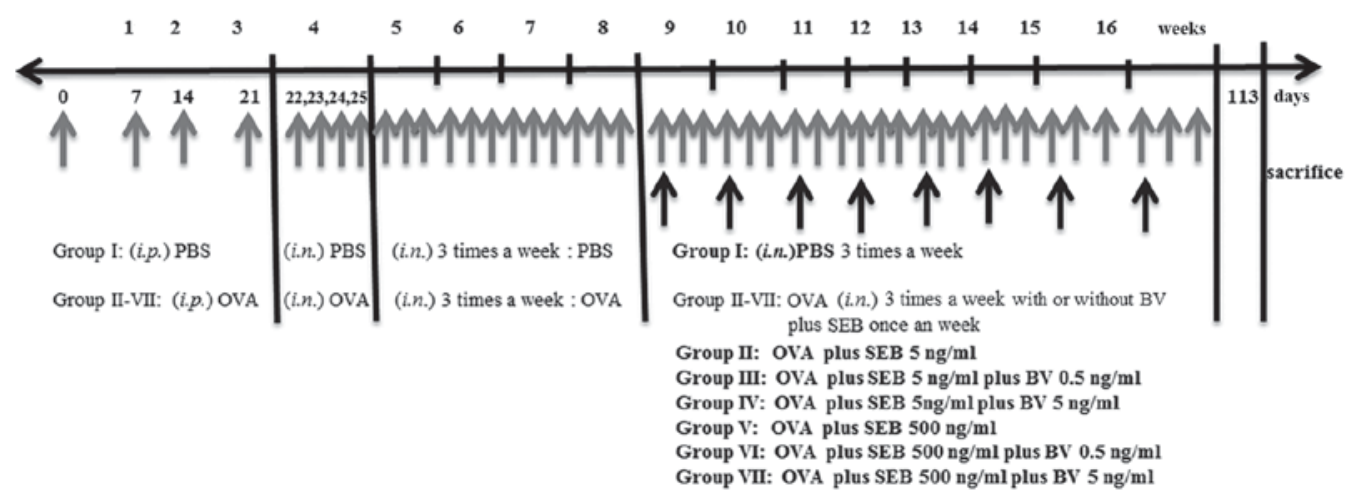

Figure 1. Schematic diagram of OVA-sensitized SEB induces an allergic CRS mouse model. BV was applied (i.n.) 3 times a week from 9 weeks through 16 weeks. Gray arrows indicate BV administration, and black arrows indicate SEB administration. OVA, ovalbumin; SEB, Staphylococcal enterotoxin B; CRS, chronic rhinosinusitis; BV, bee venom; i.p., intraperitoneal; i.n., intranasally.
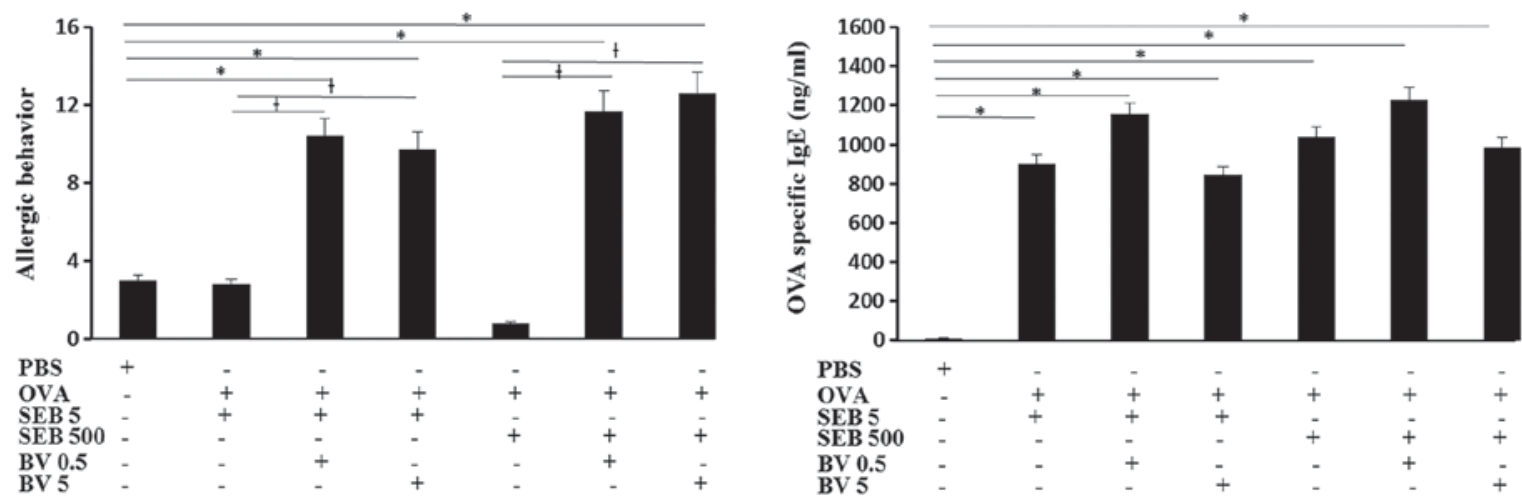

Figure 2. Effects of BV on serum OVA specific IgE levels, and allergic behavior in 5 and $500 \mathrm{ng} / \mathrm{ml}$ of SEB induces an allergic CRS mouse model. The total number of sneezing occurrences and rubbing motions were significantly increased with BV at a concentration of $0.5 \mathrm{and} 5 \mathrm{ng} / \mathrm{ml}$. ${ }^{*} \mathrm{P}<0.05 \mathrm{vs}$. PBS group; ${ }^{\mathrm{P}} \mathrm{P}<0.05$ vs. SEB challenged group. OVA, ovalbumin; SEB, Staphylococcal enterotoxin B; CRS, chronic rhinosinusitis; BV, bee venom; IgE, immunoglobulin E.

reacted with 3,3'-diaminobenzidine tetrahydrochloride and $0.02 \% \mathrm{H}_{2} \mathrm{O}_{2}$ in Tris- $\mathrm{HCl}$ buffer for color development. A minimum of three sections were analyzed per mouse. Images were captured with a Nikon ECLIPSE 80i microscope (Nikon Corporation, Tokyo, Japan) and i-Solution (IMT i-Solution; v11.0, Burlington, ON, Canada) was used to measure NF- $\kappa$ B p65-positive and AP-1 c-Jun-positive areas in epithelial area.

Statistical analysis. All measured parameters are expressed as the mean standard error of mean for each group and are representative of seven independent experiments. The one-way analysis of variance followed by Tukey's test for normally distributed data and the Kruskal-Wallis tests with post-hoc Bonferroni-Dunn test for nonnormally distributed data (SPSS Inc., Chicago, IL, USA). P $<0.05$ was considered to indicate a statistically significant difference.

\section{Results}

Serum OVA specific IgE and allergic behavior. Serum OVA specific IgE level was significantly increased in OVA and SEB treated mouse and BV did not inhibited OVA specific IgE level. The total number of sneezing and nasal rubbing motion for 15 min was determined as allergic behavior. When the OVA challenged mouse was treated with SEB, allergic behavior was

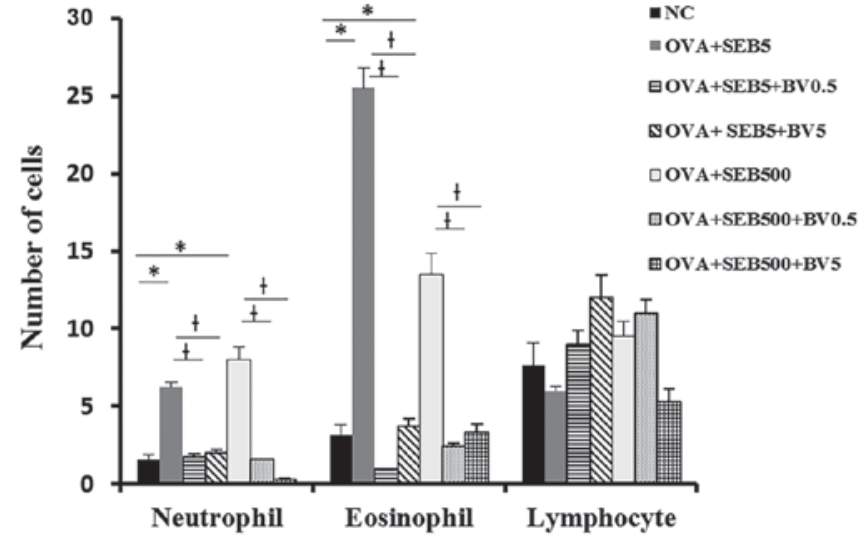

Figure 3. Effects of BV on inflammatory differentials in the nasal lavage fluid of the SEB allergic CRS mouse model. Neutrophil and eosinophil counts were significantly decreased with the intranasal application of $\mathrm{BV}$. ${ }^{\text {"P }}<0.05$ vs. NC; ${ }^{\dagger} \mathrm{P}<0.05$ vs. SEB challenged group. NC, negative control; OVA, ovalbumin; SEB, Staphylococcal enterotoxin B; CRS, chronic rhinosinusitis; BV, bee venom.

not significantly different from control group. When the OVA sensitized mouse were challenged with SEB then treated with $\mathrm{BV}$, allergic behavior was much increased compare with SEB treated alone and control groups (Fig. 2). 

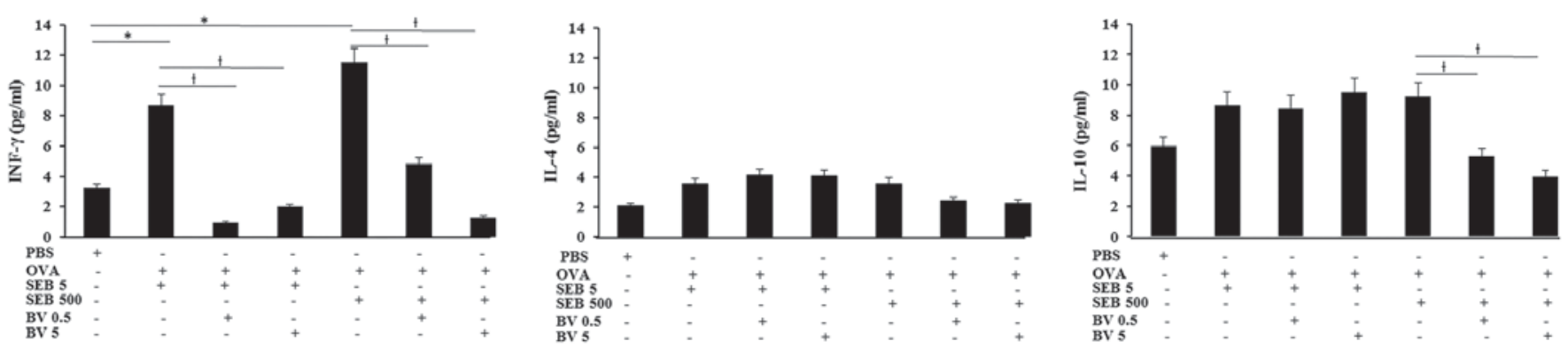

Figure 4. Effects of BV on the production of IL-4, IL-10 and INF- $\gamma$ in the nasal lavage fluid of the SEB allergic CRS mouse model. SEB induced INF- $\gamma$ production was significantly inhibited with $\mathrm{BV}$ at concentration of 0.5 and $5 \mathrm{ng} / \mathrm{ml} .{ }^{*} \mathrm{P}<0.05 \mathrm{vs}$. PBS group; ${ }^{\dagger} \mathrm{P}<0.05$ vs. SEB challenged group. IL, interleukin; IFN, interferon; OVA, ovalbumin; SEB, Staphylococcal enterotoxin B; CRS, chronic rhinosinusitis; BV, bee venom.

Inflammatory cells and cytokine levels in NLF. Neutrophils and eosinophils were significantly increased NLF in allergic CRS model (neutrophil: $6.3 \pm 3.2$, eosinophil: $25.5 \pm 13.6$ with $5 \mathrm{ng} / \mathrm{ml}$ of SEB, neutrophil $8.0 \pm 3.7$, eosinophil: $13.5 \pm 2.7$ with $500 \mathrm{ng} / \mathrm{ml}$ of SEB). These inflammatory cell infiltrations were significantly decreased when the mouse were treated with BV intranasally (Fig. 3).

INF- $\gamma$ levels in NLF displayed significantly increase in allergic CRS model (SEB $5 \mathrm{ng} / \mathrm{ml}: 8.7 \pm 3.6 \mathrm{pg} / \mathrm{ml}$, SEB $500 \mathrm{ng} / \mathrm{ml}: 11.5 \pm 6.2 \mathrm{pg} / \mathrm{ml}$, respectively), compared with control group $(3.2 \pm 2.5 \mathrm{pg} / \mathrm{ml})$. Increased level of INF- $\gamma$ in allergic CRS model made with SEB was significantly suppressed by $0.5 \mathrm{ng} / \mathrm{ml}$ of BV (SEB $5 \mathrm{ng} / \mathrm{ml}: 0.9 \pm 0.2 \mathrm{pg} / \mathrm{ml}$, SEB $500 \mathrm{ng} / \mathrm{ml}: 4.8 \pm 2.1 \mathrm{pg} / \mathrm{ml}$, respectively) and $5 \mathrm{ng} / \mathrm{ml}$ of BV (SEB $5 \mathrm{ng} / \mathrm{ml}: 2.0 \pm 0.7 \mathrm{pg} / \mathrm{ml}$, SEB $500 \mathrm{ng} / \mathrm{ml}: 1.3 \pm 0.7 \mathrm{pg} / \mathrm{ml}$, respectively). Although the IL-10 level in allergic CRS is not significantly increased, IL-10 level in the allergic CRS model made with $500 \mathrm{ng} / \mathrm{ml}$ of SEB $(9.2 \pm 4.3 \mathrm{pg} / \mathrm{ml})$ was significantly suppressed by BV (BV $0.5 \mathrm{ng} / \mathrm{ml}: 5.3 \pm 2.7 \mathrm{pg} / \mathrm{ml}$, BV $5 \mathrm{ng} / \mathrm{ml}$ : $3.9 \pm 2.1 \mathrm{pg} / \mathrm{ml}$, respectively). However, IL-4 level was not significantly different among allergic CRS model and control groups (Fig. 4).

Histological changes. All experimental groups showed an increased inflammatory cell infiltration of the submucosal area than control group $(0.4 \pm 0.2)$. Inflammatory cell infiltrations in allergic CRS mouse model (OVA with $5 \mathrm{ng} / \mathrm{ml}$ of SEB: $2.4 \pm 0.5$, OVA with $500 \mathrm{ng} / \mathrm{ml}$ of SEB: $2.6 \pm 0.3$ ) were significantly decreased with $0.5 \mathrm{ng} / \mathrm{ml}$ of BV (Fig. 5).

Thickness of epithelial cells in nasal mucosa showed a significant increase in all experimental groups compared with the control group $(34.5 \pm 14.2 \mu \mathrm{m})$. BV did not have a significant influence on the thickness of epithelial cells. Mucins producing PAS-positive cells were significantly increased in all experimental groups compared with control group. When the allergic CRS mouse models were treated with BV, PAS-positive cell numbers were significantly decreased by 0.5 and $5 \mathrm{ng} / \mathrm{ml}$ of BV (Fig. 5).

$\mathrm{NF}-\mathrm{KB}$ and AP-1 expression were determined with imuunohistochemical staining. NF- $\kappa \mathrm{B}$ and AP-1 expressions were significantly increased in allergic CRS mouse model. NF- $\kappa \mathrm{B}$ expression was stronger than AP-1 and SEB induced NF- $\mathrm{KB}$ and AP-1 expressions were significantly suppressed by 0.5 and $5 \mathrm{ng} / \mathrm{ml}$ of BV (NF- $\mathrm{kB}: 51-61 \%$, AP-1: 18-22\%) (Fig. 6).

\section{Discussion}

$\mathrm{BV}$ has been used as a traditional medicine to treat chronic inflammatory diseases. CRS is characterized by chronic inflammation of the nasal and paranasal sinus mucosa. In this study, we tried to certify the immunopharmacologic effect of $\mathrm{BV}$ on allergic CRS mouse model. We used 0.5 and $5 \mathrm{ng} / \mathrm{ml}$ of $\mathrm{BV}$, due to the concentrations ranging from 0.05 to $10 \mathrm{ng} / \mathrm{ml}$ did not influence the morphology of nasal mucosa and survival of mouse. More than $500 \mathrm{ng} / \mathrm{ml}$ of BV is lethal to mouse $(11,12)$. When the allergic CRS mouse models were treated with 100 and $10 \mathrm{ng} / \mathrm{ml}$ of BV, BV did not influence immune response of mouse model. Higher concentrations of BV triggered the production of chemical mediators from nasal epithelial cells and keratinocytes. In contrast, relatively low concentrations of $\mathrm{BV}$ inhibited the production of chemical mediators from these cells $(11,14)$. The anti-inflammatory effect of BV is caused at relatively low concentrations (15). BV may exhibit different immunologic activities depending on the dosage and type of treated cells. BV suppressed Th1 cytokine, INF- $\gamma$ production and mucin producing cells in nasal mucosa. These finding shows that BV could be therapeutic agent to improve the inflammatory condition of CRS.

Allergic CRS mouse model made with SEB is characterized as eosinophilic CRS as a result of immunologic dysfunction of nasal mucosa and can reflect the immunologic change after treat with various medical agents (5). When the OVA sensitized mouse were challenged with SEB, inflammatory cell infiltration in nasal mucosa, eosinophil and neutrophil count in nasal secretion, and INF- $\gamma$ level were significantly increased. In allergic CRS mouse model, eosinophils, neutrophils, lymphocytes, mast cells and some other inflammatory cells are found in nasal mucosa (5). In the present study, we observed inflammatory cells in NLF, inflammatory cell differential counts were focused on the eosinophils, neutrophils, and lymphocytes. Although IL-4 level in NLF tends to increase in allergic CRS mouse model, it was not statistically significant. BV had anti-inflammatory effect with inhibition of inflammatory cell infiltration and INF- $\gamma$ production. Although we cannot determine the exact components which influence the anti-inflammatory effect on allergic CRS model, BV seems to significantly influence the Th1 inflammatory reaction. BV consists of several biologically active peptides, enzymes and amines with a variety of pharmaceutical characteristics. Melittin and adolapin, the main components of $\mathrm{BV}$, have anti-inflammatory properties that 


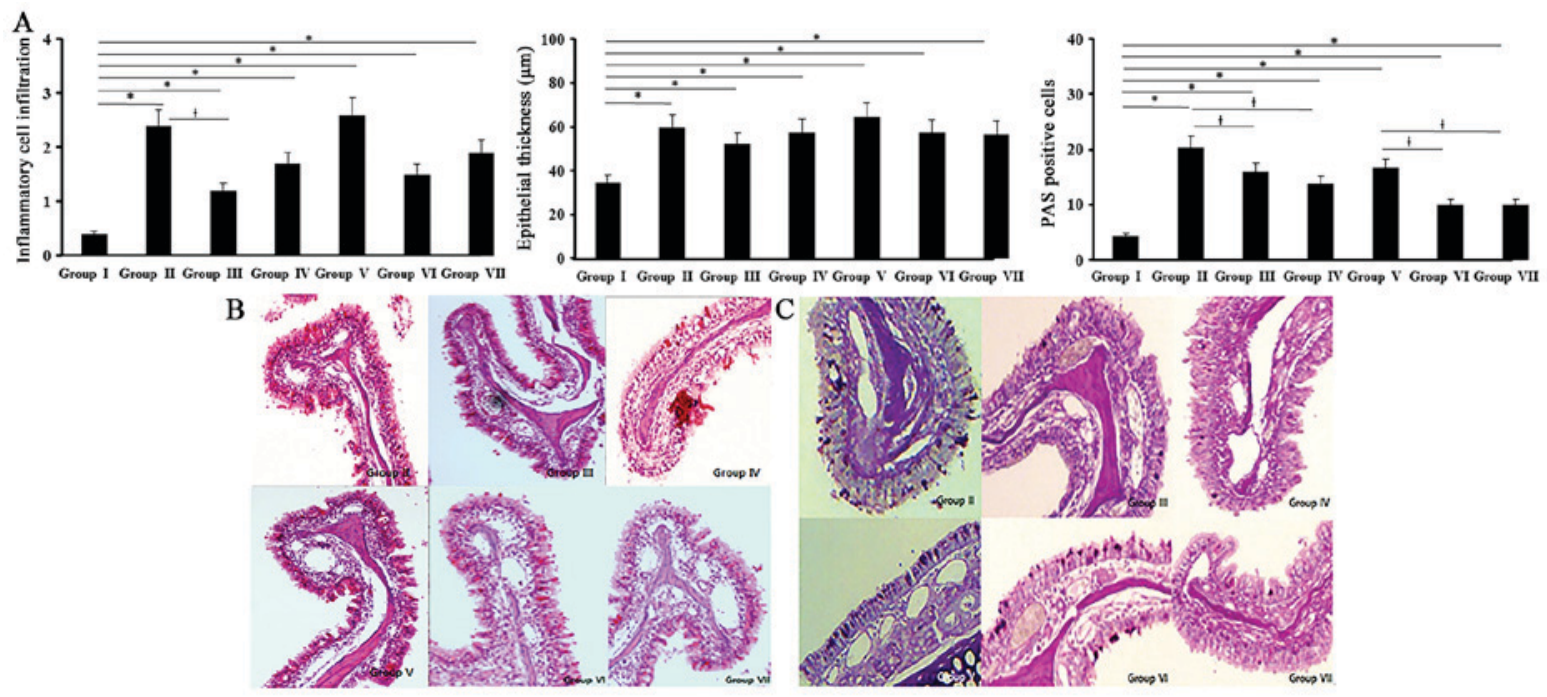

Figure 5. (A) Effects of BV on the histological alterations in the SEB allergic CRS mouse model. Representative histological sections stained with (B) hematoxylin and eosin stainving and (C) PAS staining was used to evaluate mucus producing cells. Although inflammatory cell infiltration and PAS positive cells were significantly decreased, epithelial thickness was not influenced by intranasal instillation of BV. The number of PAS positive cells was decreased at 0.5 and $5 \mathrm{ng} / \mathrm{ml}$ of BV. Original magnification, $\mathrm{x} 400$. " $\mathrm{P}<0.05$ vs. Group I; ${ }^{\circ} \mathrm{P}<0.05$ vs. Group II or Group V (as indicated). PAS, periodic acid-Schiff; SEB, Staphylococcal enterotoxin B; CRS, chronic rhinosinusitis; BV, bee venom.
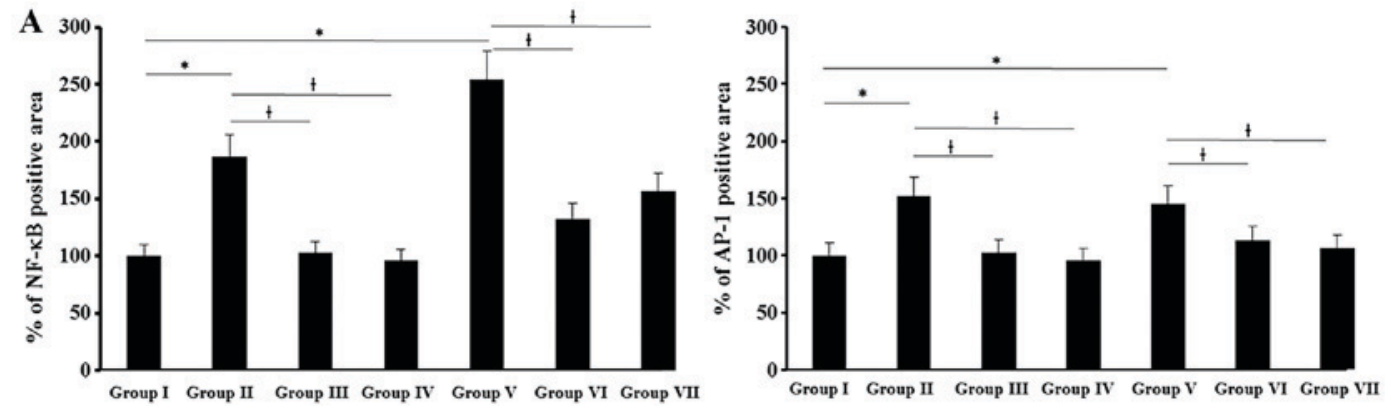

B

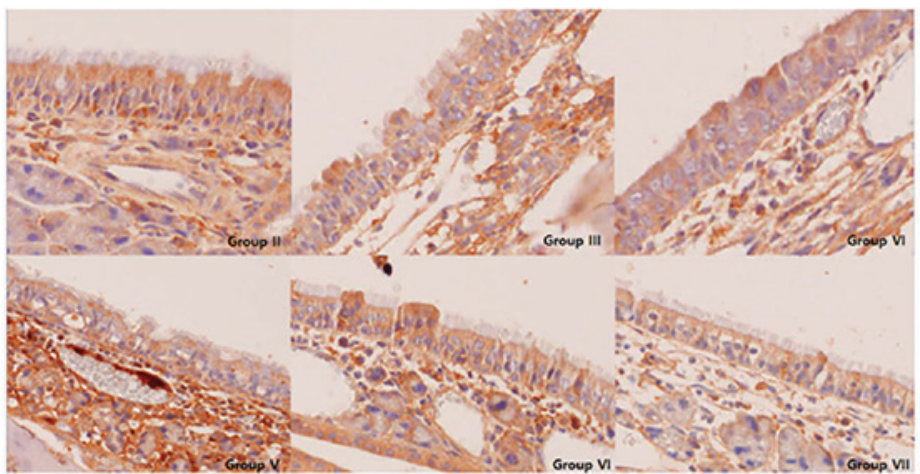

Figure 6. Effects of BV on the expression of NF- $\mathrm{B}$ and AP-1 in immunohistochemical sections of the SEB allergic CRS mouse model. (A) Morphometric analysis was performed to determine NF- $\mathrm{KB}$ and AP-1 positive areas in epithelial area. (B) Representative histological sections show immunohistochemical staining for NF- $\mathrm{KB}$ in nasal mucosa. SEB-induced NF- $\mathrm{\kappa B}$ and AP-1 expressions were significantly suppressed with BV at concentration of 0.5 and $5 \mathrm{ng} / \mathrm{ml}$. Original magnification, $\mathrm{x} 400$. " $\mathrm{P}<0.05$ vs. Group I; 'P $<0.05$ vs. Group II or Group V (as indicated). NF, nuclear factor; AP, activator protein; SEB, Staphylococcal enterotoxin B; CRS, chronic rhinosinusitis; BV, bee venom.

involve inhibition of cyclooxygenase-2 and phospholipase A2 (PLA2) expression and suppress the production of IL-1, IL-6, and tumor necrosis factor- $\alpha$ from inflammatory cells (10). According to the previous study with allergic mouse model, BV and nano-silver has anti-allergic effect in an animal model of allergic rhinitis with significantly decreased IL-4 and eosinophils in nasal secretion $(12,16)$. Allergic mouse model shows Th2 predominant immune response and allergic CRS mouse model has both Th1 and Th2 immune response with increased Th1 and Th2 cytokines in NLF. These finding can suggest BV has not only influence the Th1 but also Th2 immune responses.

Nasal epithelial cells in CRS has squamous metaplasia, ciliary destruction, and increased mucous gland and goblet cell hyperplasia with basement membrane thickening. Improving the tissue remodeling in CRS is an important therapeutic target. BV decreased PAS positive cells, which represent BV might 
suppress the production of mucus from nasal mucosa, but did not influence the thickness of epithelial layer. We cannot make conclusion whether BV influence the tissue remodeling of CRS. Eight weeks intranasal application of BV is not sufficient to suppress the fibrotic change or tissue remodeling process in nasal mucosa. The mucosal structural change in mouse model may not be a transient but a permanent.

Although intranasal application of BV suppressed inflammatory response in CRS mouse model, BV did not inhibited serum OVA specific IgE level and allergic symptoms were aggravated. Which means, BV, itself can induce severe allergic reaction due to multiple protein allergens with enzymatic activity. Mast cell degranulating peptide in BV, one of the most potent natural histamine secretagogues, and PLA2, a major inflammatory component of $\mathrm{BV}$, can induce allergic reactions $(9,17)$. These compounds of $\mathrm{BV}$ might strongly influence the immune response of nasal epithelial cells then may induce allergic symptoms in allergic CRS mouse model. Allergic CRS model was made with OVA and SEB. SEB also can induce allergic response with the stimulation $\mathrm{B}$ cells and local IgE production. In this study, OVA, SEB, and BV might synergistically affect the allergic response in nasal mucosa. However, further study is needed to elucidate the exact cause of aggravated allergic symptoms in this study. BV not only has anti-inflammatory effect, but also causes a severe allergic or inflammatory reaction. For the clinical use of BV, we need to determine the optimal concentration and duration that show the maximal anti-inflammatory effects without harmful effects.

$\mathrm{NF}-\kappa \mathrm{B}$ and AP-1 are transcription factor that orchestrate the expression of many genes involved in inflammation. During the genetic process of inflammation, many genes require concomitantly to activate $\mathrm{NF}-\kappa \mathrm{B}$ and AP-1 pathway and these transcription factors works in cooperation (18). In-vitro study with nasal polyp epithelial cells, BV inhibits airborne allergen-induced cytokine production by inhibiting the NF- $\mathrm{B}$ and AP-1 pathways (11). Nasal mucosa of OVA sensitized mouse then challenged with $\mathrm{SEB}, \mathrm{NF}-\kappa \mathrm{B}$ expression was more strongly increased than AP-1 and these increase $\mathrm{NF}-\kappa \mathrm{B}$ and AP-1 expressions were significantly inhibited by BV. The anti-inflammatory effect of BV in allergic CRS model was associated with the inhibition of NF- $\mathrm{KB}$ and AP-1. However, $\mathrm{NF}-\kappa \mathrm{B}$ seems to be more important in the inflammatory reaction of CRS model. These results support the previous study that BV suppresses the lipopolysaccharide induced production of chemical mediators through blocking the prime signaling pathway, including Akt, NF- $\mathrm{B}, \mathrm{ERK} 1 / 2$, and AP-1 (15). Melittin in BV inhibits the DNA-binding activity of $\mathrm{NF}-\kappa \mathrm{B}$ by inhibiting I $\kappa$ B phosphorylation (19). Adolapin also has anti-inflammatory activity through its ability to inhibit prostaglandin synthesis, and NF- $\mathrm{NB}$ is involved in the regulation of the arachidonic acid pathway (7). These anti-inflammatory components may associate with the inhibition of $\mathrm{NF}-\kappa \mathrm{B}$ and AP-1 activity in allergic CRS mouse model.

In summary, BV has significant anti-inflammatory effect in an animal model of allergic CRS. The anti-inflammatory effect of BV is associated with the inhibition of Th1 cytokine production, inflammatory cell infiltration in nasal mucosa and mucus production. These anti-inflammatory characteristics of $\mathrm{BV}$ are associated with inhibition of $\mathrm{NF}-\kappa \mathrm{B}$ and $\mathrm{AP}-1$ pathway. Although, 0.5 and $5 \mathrm{ng} / \mathrm{ml}$ of $\mathrm{BV}$ is effect to control the inflammation of allergic CRS, further studies are needed to determine optimal concentration of BV for clinical usage and the anti-inflammatory characteristics of each components of BV. Our data suggest a novel pharmacological rationale for the treatment of CRS and BV can be use as adjuvant agent which enhance the therapeutic potency and minimize adverse effect of modern anti-inflammatory medications.

\section{Acknowledgements}

Not applicable.

\section{Funding}

The present study was carried out with the support of 'Cooperative Research Program for Agriculture Science and Technology Development (project no. PJ01132501)' Rural Development Administration, Republic of Korea. This research was also supported by The Basic Science Research Program through the National Research Foundation of Korea (NRF) funded by the Ministry of Education, Science and Technology (grant no. 2010-0023163).

\section{Availability of data and materials}

The analyzed data sets generated during the study are available from the corresponding author on reasonable request.

\section{Authors' contributions}

SHS and KKP designed the study and the experimental protocol. MKY and SC performed the experiments, and SHS, KKP and MKY analyzed the data. SHS and SC wrote the manuscript. All authors contributed to and approved the final manuscript.

\section{Ethics approval and consent to participate}

The present study was approved by the Institutional Review Board of Animal Experiments of Daegu Catholic University Medical Center (Daegu, Republic of Korea).

\section{Consent for publication}

Not applicable.

\section{Competing interests}

The authors declare that they have no competing interests.

\section{References}

1. Bachert C, Zhang N, Holtappels G, Bachert C, Zhang N, Holtappels G, De Lobel L, van Cauwenberge P, Liu S, Lin P, et al: Presence of IL-5 protein and IgE antibodies to staphylococcal enterotoxins in nasal polyps is associated with comorbid asthma. J Allergy Clin Immunol 126: 962-968, 2010.

2. Wang X, Du J and Zhao C: Bacterial biofilms are associated with inflammatory cells infiltration and the innate immunity in chronic rhinosinusitis with or without nasal polyps. Inflammation 37: 871-879, 2014.

3. Ponikau JU, Sherris DA and Kita H: The role of unbiquitous airborne fungi in chronic rhinosinusitis. Clin Allergy Immunol 20: 177-184, 2007. 
4. Van Zele T, Gevaert P, Watelet JB, Claeys G, Holtappels G, Claeys C, van Cauwenberge P and Bachert C: Staphylococcus aureus colonization and $\mathrm{IgE}$ antibody formation to enterotoxins is increased in nasal polyposis. J Allergy Clin Immunol 114: 981-983, 2004

5. Kim DW, Khalmuratova R, Hur DG, Jeon SY, Kim SW, Shin HW, Lee CH and Rhee CS: Staphylococcus aureus enterotoxin $\mathrm{B}$ contributes to induction of nasal polypoid lesions in an allergic rhinosinusitis murine model. Am J Rhinol Allergy 25: e255-e261, 2011

6. Jang MH, Shin MC, Lim S, Han SM, Park HJ, Shin I, Lee JS, Kim KA, Kim EH and Kim CJ: Bee venom induces apoptosis and inhibits expression of cyclooxygenase-2 mRNA in human lung cancer cell line NCI-H1299. J Pharmacol Sci 91: 95-104, 2003.

7. Son DJ, Lee JW, Lee YH, Song HS, Lee CK and Hong JT: Therapeutic application of anti-arthritis, pain-releasing, and anti-cancer effects of bee venom and its constituent compounds. Pharmacol Ther 115: 246-270, 2007.

8. Kim JI, Yang EJ, Lee MS, Kim YS, Huh Y, Cho IH, Kang S and Koh HK: Bee venom reduces neuroinflammatin in the MPTP-induced model of parkinson's disease. Int J Neurosci 121 209-217, 2011.

9. Mousli M, Bueb JL, Bronner C, Rouot B and Landry Y: G protein activation: A receptor independent mode of action for cationic amphiphilic neuropeptides and venom peptides. Tends Pharmacol Sci 11: 358-362, 1990.

10. Shin JM, Jeong YJ, Cho HJ, Park KK, Chung IK, Lee IK, Kwak JY, Chang HW, Kim CH, Moon SK, et al: Melittin suppresses HIF-1 $\alpha /$ VEGF expression through inhibition of ERK and $\mathrm{mTOR} / \mathrm{p} 70 \mathrm{~S} 6 \mathrm{~K}$ pathway in human cervical carcinoma cell. PLoS One 8: e69380, 2013.
11. Shin SH, Ye MK, Kim JK and Park KK: Bee venom at different concentrations modulates the aeroallergen-induced activation of nasal polyp epithelial cells. Pharmacol 91: 39-47, 2013.

12. Shin SH, Kim YH, Kim JK and Park KK: Anti-allergic effect of bee venom in an allergic rhinitis mouse model. Biol Pharma Bull 37: 1295-1300, 2014.

13. Han S, Lee K, Yeo J, Kweon H, Woo S, Lee M, Baek H, Kim S and Park K: Effect of honey bee venom on microglial cells nitric oxide and tumor necrosis factor-alpha production stimulated by LPS. J Ethnopharmacol 111: 176-181, 2007.

14. Kim JY, Lee WR, Kim KH, An HJ, Chang YC, Han SM, Park YY, Pak SC and Park KK: Effects of bee venom against propionibacterium acnes-induced inflammation in human keratinocytes and monocytes. Int J Mol Med 35: 1651-1656, 2015.

15. Kim WH, An HJ, Kim JY, Gwon MG, Gu H, Park JB, Sung WJ, Kwon YC, Park KD, Han SM and Park KK: Bee venom inhibits porphyromonas gingivalis lipopolysaccharides-induced pro-inflammatory cytokines through suppression of NF- $\kappa \mathrm{B}$ and AP-1 signaling pathways. Molecules 21: pii: E1508, 2016.

16. Shin SH and Ye MK: The effect of nano-silver on allergic rhinitis model in mice. Clin Exp Otorhinolaryngol 5: 222-227, 2012.

17. Saini SS, Peterson JW and Chopra AK: Melittin binds to secretory phospholipase A2 and inhibits its enzymatic activity. Biochem Biophys Res Commun 238: 436-442, 1997.

18. Fujioka S, Niu J, Schmidt C, Sclabas GM, Peng B, Uwagawa T, Li Z, Evans DB, Abbruzzese JL and Chiao PJ: NF-kappaB and AP-1 connection: Mechanism of NF-kappaB-dependent regulation of AP-1 activity. Mol Cell Biol 24: 7806-7819, 2004.

19. Park HJ, Son DJ, Lee CW, Choi MS, Lee US, Song HS, Lee JM and Hong JT: Melittin inhibits inflammatory target gene expression and mediator generation via interaction with IkappaB kinase. Biochem Pharmacol 73: 237-247, 2007. 